\title{
Relationship between the presence of dedicated doctors in rapid response systems and patient outcome: a multicenter retrospective cohort study
}

Hyung-Jun Kim ${ }^{1 \dagger}$, Kyeongman Jeon ${ }^{2 \dagger}$, Byung Ju Kang ${ }^{3}$, Jong-Joon Ahn ${ }^{3}$, Sang-Bum Hong ${ }^{4}$, Dong-Hyun Lee ${ }^{5}$, Jae Young Moon ${ }^{6}$, Jung Soo Kim, Jisoo Park ${ }^{8}$, Jae Hwa Cho ${ }^{9}$, Sang-Min Lee ${ }^{10}$ and Yeon Joo Lee ${ }^{1^{*}}$ (D)

\begin{abstract}
Background: Rapid response systems (RRSs) improve patients' safety, but the role of dedicated doctors within these systems remains controversial. We aimed to evaluate patient survival rates and differences in types of interventions performed depending on the presence of dedicated doctors in the RRS.

Methods: Patients managed by the RRSs of 9 centers in South Korea from January 1, 2016, through December 31, 2017, were included retrospectively. We used propensity score-matched analysis to balance patients according to the presence of dedicated doctors in the RRS. The primary outcome was in-hospital survival. The secondary outcomes were the incidence of interventions performed. A sensitivity analysis was performed with the subgroup of patients diagnosed with sepsis or septic shock.

Results: After propensity score matching, 2981 patients were included per group according to the presence of dedicated doctors in the RRS. The presence of the dedicated doctors was not associated with patients' overall likelihood of survival (hazard ratio for death 1.05, 95\% confidence interval [CI] 0.93-1.20). Interventions, such as arterial line insertion (odds ratio [OR] 25.33, 95\% Cl 15.12-42.44) and kidney replacement therapy (OR 10.77, 95\% Cl 6.10-19.01), were more commonly performed for patients detected using RRS with dedicated doctors. The presence of dedicated doctors in the RRS was associated with better survival of patients with sepsis or septic shock (hazard ratio for death $0.62,95 \% \mathrm{Cl} 0.39-0.98$ ) and lower intensive care unit admission rates (OR $0.53,95 \% \mathrm{Cl} 0.37-0.75$ ).

Conclusions: The presence of dedicated doctors within the RRS was not associated with better survival in the overall population but with better survival and lower intensive care unit admission rates for patients with sepsis or septic shock.
\end{abstract}

Keywords: Hospital rapid response system, Propensity score, Physicians, Mortality

*Correspondence: yjlee1117@snubh.org

${ }^{\dagger}$ Hyung-Jun Kim and Kyeongman Jeon contributed equally to this work

1 Division of Pulmonary and Critical Care Medicine, Department

of Internal Medicine, Seoul National University Bundang Hospital,

Seongnam, Republic of Korea

Full list of author information is available at the end of the article

(c) The Author(s) 2021. Open Access This article is licensed under a Creative Commons Attribution 4.0 International License, which permits use, sharing, adaptation, distribution and reproduction in any medium or format, as long as you give appropriate credit to the original author(s) and the source, provide a link to the Creative Commons licence, and indicate if changes were made. The images or other third party material in this article are included in the article's Creative Commons licence, unless indicated otherwise in a credit line to the material. If material is not included in the article's Creative Commons licence and your intended use is not permitted by statutory regulation or exceeds the permitted use, you will need to obtain permission directly from the copyright holder. To view a copy of this licence, visit http://creativecommons.org/licenses/by/4.0/. The Creative Commons Public Domain Dedication waiver (http://creativeco mmons.org/publicdomain/zero/1.0/) applies to the data made available in this article, unless otherwise stated in a credit line to the data. 


\section{Background}

Rapid response systems (RRS) are staffed by critical care experts and aimed to identify hospitalized patients at risk of rapid deterioration, enabling suitable interventions to be delivered before a catastrophic event [1]. Unlike the traditional code team, RRS are activated before a code situation occurs, as cardiac arrests are commonly preceded by premonitory signs and symptoms [2]. RRS have been widely deployed after the 100,000 Lives Campaign to reduce the number of preventable deaths [3]. Their implementation can reduce hospital mortality rates and non-intensive care unit (ICU) cardiopulmonary arrests [4].

The RRS teams usually include medical doctors, nurses, respiratory therapists, or pharmacists [5]. However, the optimal composition of these teams is controversial, and it may differ according to staff and resource availability at each center [6, 7]. Some RRS have dedicated doctors that do not have any other clinical obligations, while others include only dual appointment doctors whose primary duties are outside of the RRS [8]. Nurse practitioners are a reasonable substitute for medical doctors in some emergency care activities, suggesting hospitals may consider the cost-effectiveness of including dedicated doctors in the RRS, as some of their duties can be effectively performed by nurses [9].

Nevertheless, whether the presence of dedicated doctors in the RRS leads to better outcomes remains controversial. Actions such as those of lung care, oxygen supplementation, or fluid administration can be effectively performed by nurses without doctors on duty; thus, the presence of dedicated doctors within the RRS may not directly influence patient outcomes [10]. However, interventions such as central line insertion and endotracheal intubation can be more effectively performed when a physician has direct contact with the deteriorating patient. It would be considerably easier to recommend the optimal composition of the RRS if patient outcomes in the presence of dedicated doctors in the RRS are evaluated. In this study, we aimed to evaluate the differences in patient outcomes when dedicated doctors were present in the RRS. This is the first multicenter study to investigate this issue.

\section{Methods}

\section{Data source and patient selection}

The study participants were included in a nationwide multicenter retrospective cohort of nine RRS-operating referral centers in South Korea. Adult (aged $\geq 18$ years) patients detected by any of these RRS from January 1 , 2016, through December 31, 2017, were included. Each hospital had its own RRS activation criteria, including abnormal vital signs, mental status change, airway compromise, chest discomfort, extreme values of laboratory findings, or subjective concern expressed by the attending medical staff (details of these criteria per hospital are included in Additional file 1). Patients who activated the RRSs from the emergency or outpatient department, the ICU, or transferred to another hospital after RRS activation were excluded from this cohort.

The cohort data included information on patient demographic characteristics, comorbidities, location and time of the RRS activation, early warning scores such as the Modified Early Warning Score (MEWS) at the time of RSS activation [11], laboratory findings, types of interventions performed, and patient outcomes including mortality. The data were extracted retrospectively after reviewing the electronic medical records by trained nurses in each hospital. The development of this cohort was approved by the Institutional Review Board of each center, and the need for informed consent was waived due to the observational nature of the study and the use of anonymized data. Our study was conducted in accordance with the amended Declaration of Helsinki.

For propensity score-matched analysis, patients with missing data on the variables of interest, and those who remained hospitalized as of 31 December 2017, were excluded. We also excluded patients for whom the reason for RRS activation was unknown, as such patients are associated with high heterogeneity, which may affect propensity score matching.

\section{Definition of the propensity score and study outcomes}

To control the impact of confounding factors on patients' assignment to a hospital with dedicated doctors in the RRS, we used propensity score-matched analysis [12]. The propensity score was defined as the patients' probability of being hospitalized at a center with dedicated doctors in the RRS. A "dedicated doctor" was defined as a medical doctor with expertise in critical care that worked exclusively for the RRS without any other clinical obligations. A dedicated doctor was present in three of nine centers.

The primary outcome was the likelihood of survival after RRS activation. The secondary outcome was the incidence of interventions performed after RRS activation, confined to those performed in the general ward before ICU admission. These interventions were grouped into 18 categories: advanced cardiovascular life support, extracorporeal membrane oxygenation, kidney replacement therapy, intubation, mechanical ventilation, bilevel positive airway pressure use, high-flow nasal cannula use, vasopressors use, bronchoscopy, arterial line insertion, central line insertion, portable sonography, computed tomography $(\mathrm{CT})$, transfusion, antibiotics use, general 
management consultation, do not resuscitate (DNR) consultation, and ICU admission.

\section{Variable selection, balance assessment, and treatment effect estimates}

Variables with a possible effect on both treatment assignment (detected by RRS with vs. without dedicated doctors) and the primary outcome (likelihood of survival) were included in the matching process [13]. This included age, sex, body mass index, comorbidities, MEWS, location of RRS activation, and reason for the RRS activation. For propensity score matching, 1:1 matching without replacement using the nearest neighbor method was used with the caliper of 0.2 [13, 14]. Standardized mean differences (SMDs) were calculated before and after matching to assess the balance of measured covariates [15].

Given the matched nature of this study, treatment effects were estimated using methods appropriate for paired samples $[15,16]$. We used Cox regression for matched pairs to assess in-hospital survival outcomes, and hazard ratios (HRs) were calculated stratified [15]. For binary outcomes, we used conditional logistic regression analysis, in which odds ratios (ORs) were calculated [15].

\section{Sensitivity analysis}

Due to the heterogeneity of RRS activation triggers, we included patients with sepsis or septic shock in sensitivity analyses, as this patient group is homogenous in its requirement of early intervention [17, 18]. Sepsis and septic shock were defined according to the Third International Consensus Definitions for Sepsis and Septic Shock [19]. As in our main analysis, patients were matched, the balance was assessed, and the treatment effect was estimated.

\section{Other statistical considerations}

Categorical variables were presented as counts with percentages, and continuous variables were presented as means with standard deviations or $95 \%$ confidence intervals $(\mathrm{CI}) . \mathrm{SMD}$ of $<0.1$ was considered negligible $[15$, 20]. Propensity score matching was performed with the "MachIt" package in $\mathrm{R}$ version 4.0.3 (The $\mathrm{R}$ Foundation for Statistical Computing, Vienna, Austria) [21].

\section{Results}

\section{Patient characteristics before matching}

During the study period, 12,803 patients were included in the retrospective multicenter cohort. Patients with missing data, those who remained hospitalized as of 31 December 2017, and those with an unknown reason for RRS activation were excluded. Finally, 9,073 patients were included in this study. Among them, 5277 patients (58.2\%) were detected by the RRS with dedicated doctors (Fig. 1).

Patients detected by the RRS with dedicated doctors were younger (mean age 62.90 vs $67.90, \mathrm{SMD}=0.348$ ) than those detected by the RSS without any dedicated

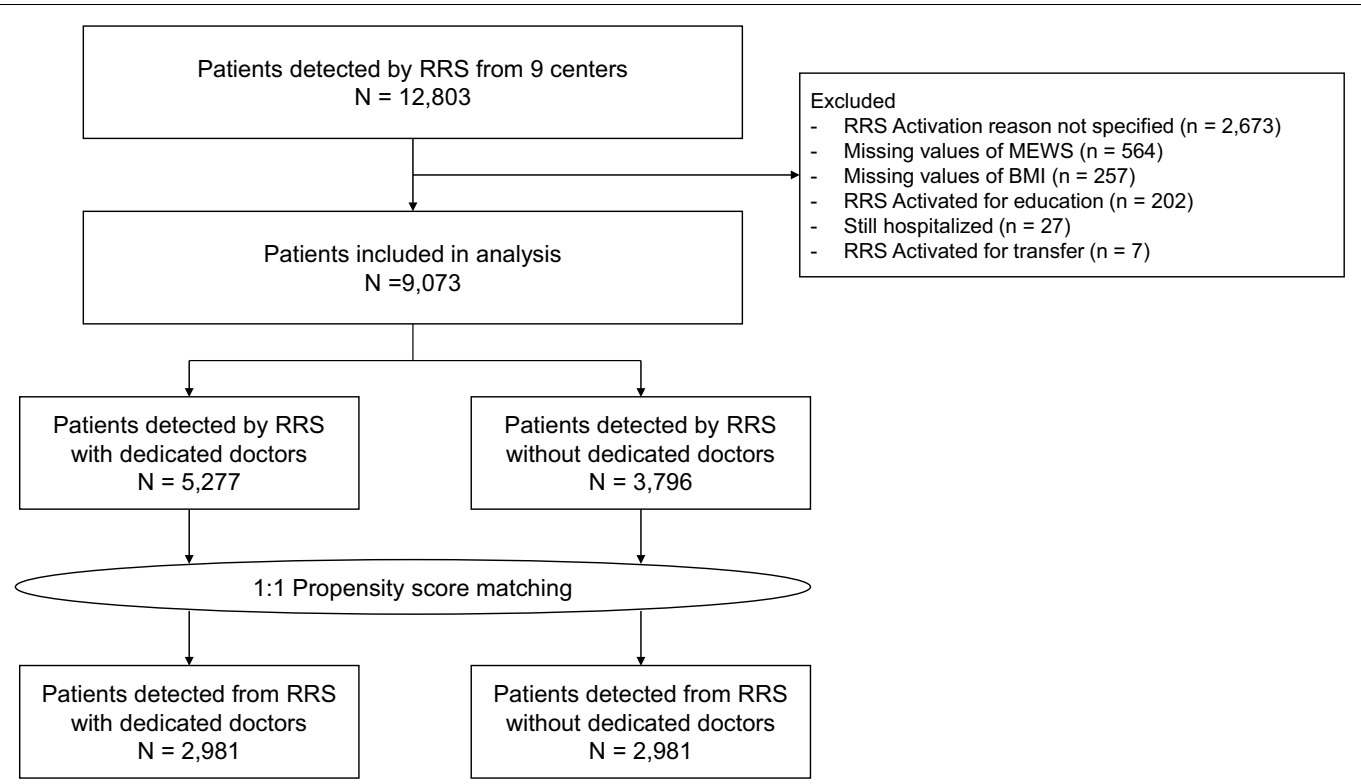

Fig. 1 Flowchart of the patient selection process. Abbreviations: BMI, body mass index; MEWS, modified early warning score; RRS, rapid response system 
doctors; however, the sex (female sex $39.2 \%$ vs $43.3 \%$, $\mathrm{SMD}=0.084$ ) and body mass index (mean 22.38 vs 22.28 , $\mathrm{SMD}=0.021)$ compositions of both groups were similar. Patients detected by the RRS with dedicated doctors had a higher incidence of solid ( $46.9 \%$ vs $30.6 \%, \mathrm{SMD}=0.338)$ and hematologic $(15.4 \%$ vs $4.9 \%, \mathrm{SMD}=0.353)$ malignancies, and that of organ transplant $(5.0 \%$ vs $1.9 \%$, SMD $=0.170$ ), but lower incidence of diabetes mellitus $(24.9 \%$ vs $29.6 \%, \mathrm{SMD}=0.106)$, chronic kidney disease $(8.8 \%$ vs $12.7 \%, \mathrm{SMD}=0.126)$, and cerebrovascular

Table 1 Characteristics of patients before and after propensity score matching

\begin{tabular}{|c|c|c|c|c|c|c|}
\hline \multirow[t]{2}{*}{ Variables } & \multicolumn{3}{|l|}{ Before matching } & \multicolumn{3}{|l|}{ After matching } \\
\hline & $\begin{array}{l}\text { RRS with dedicated } \\
\text { doctor } n=5277\end{array}$ & $\begin{array}{l}\text { RRS without dedicated } \\
\text { doctor } n=3796\end{array}$ & SMD & $\begin{array}{l}\text { RRS with dedicated } \\
\text { doctor } n=2981\end{array}$ & $\begin{array}{l}\text { RRS without dedicated } \\
\text { doctor } n=2981\end{array}$ & SMD \\
\hline Age, years & $62.90 \pm 14.36$ & $67.90 \pm 14.39$ & 0.348 & $66.32 \pm 13.46$ & $66.83 \pm 14.57$ & 0.037 \\
\hline Female sex & $2067(39.2)$ & $1643(43.3)$ & 0.084 & $1203(40.4)$ & $1241(41.6)$ & 0.026 \\
\hline Body mass index, kg/m² & $22.38 \pm 4.62$ & $22.28 \pm 4.43$ & 0.021 & $22.26 \pm 4.7$ & $22.35 \pm 4.48$ & 0.020 \\
\hline \multicolumn{7}{|l|}{ Comorbidities } \\
\hline Solid malignancy & $2473(46.9)$ & $1163(30.6)$ & 0.338 & $1117(37.5)$ & $1069(35.9)$ & \\
\hline Cardiovascular disease & $1329(25.2)$ & $892(23.5)$ & 0.039 & $777(26.1)$ & $733(24.6)$ & 0.033 \\
\hline Diabetes mellitus & $1315(24.9)$ & 1125 (29.6) & 0.106 & $821(27.5)$ & $830(27.8)$ & 0.034 \\
\hline Hematologic malignancy & $811(15.4)$ & $185(4.9)$ & 0.353 & $197(6.6)$ & $182(6.1)$ & 0.007 \\
\hline Chronic lung disease & $715(13.5)$ & $577(15.2)$ & 0.047 & $503(16.9)$ & $474(15.9)$ & 0.021 \\
\hline Chronic HBP disease & $602(11.4)$ & $370(9.7)$ & 0.054 & $311(10.4)$ & $302(10.1)$ & 0.026 \\
\hline Chronic kidney disease & $463(8.8)$ & $481(12.7)$ & 0.126 & $353(11.8)$ & $359(12.0)$ & 0.010 \\
\hline Cerebrovascular disease & $364(6.9)$ & $636(16.8)$ & 0.309 & $320(10.7)$ & $384(12.9)$ & 0.006 \\
\hline Organ Transplantation & $263(5)$ & $72(1.9)$ & 0.170 & $77(2.6)$ & $67(2.2)$ & 0.067 \\
\hline Gastrointestinal disease & $173(3.3)$ & $181(4.8)$ & 0.076 & $125(4.2)$ & $129(4.3)$ & 0.022 \\
\hline Thyroid disease & $135(2.6)$ & $123(3.2)$ & 0.041 & $87(2.9)$ & $84(2.8)$ & 0.007 \\
\hline MEWS & $4.75 \pm 2.16$ & $4.03 \pm 2.23$ & 0.326 & $4.28 \pm 2.06$ & $4.21 \pm 2.26$ & 0.030 \\
\hline Department & & & 0.322 & & & 0.034 \\
\hline Medical & $4130(78.3)$ & $2439(64.3)$ & & $2127(71.4)$ & $2082(69.8)$ & \\
\hline Surgical & $1117(21.2)$ & $1345(35.4)$ & & $841(28.2)$ & $887(29.8)$ & \\
\hline Obstetrics & $30(0.6)$ & $12(0.3)$ & & $13(0.4)$ & $12(0.4)$ & \\
\hline Location & & & 0.014 & & & 0.014 \\
\hline General ward & $5181(98.2)$ & $3726(98.2)$ & & $2925(98.1)$ & $2923(98.1)$ & \\
\hline Examination unit & $69(1.3)$ & $48(1.3)$ & & $40(1.3)$ & $40(1.3)$ & \\
\hline Dialysis unit & $13(0.2)$ & $12(0.3)$ & & $6(0.2)$ & $8(0.3)$ & \\
\hline Others & $14(0.3)$ & $10(0.3)$ & & $10(0.3)$ & $10(0.3)$ & \\
\hline Reason for activation & & & 0.499 & & & 0.098 \\
\hline Respiratory distress & $2452(46.5)$ & $1797(47.3)$ & & $1518(50.9)$ & $1462(49)$ & \\
\hline Hypovolemic shock & $483(9.2)$ & $164(4.3)$ & & $156(5.2)$ & $149(5)$ & \\
\hline Arrhythmias & $478(9.1)$ & $253(6.7)$ & & $241(8.1)$ & $238(8)$ & \\
\hline Septic shock & $402(7.6)$ & $203(5.3)$ & & $181(6.1)$ & $182(6.1)$ & \\
\hline Altered mental status & $381(7.2)$ & $144(3.8)$ & & $140(4.7)$ & $128(4.3)$ & \\
\hline Sepsis & $292(5.5)$ & $115(3)$ & & $118(4)$ & $110(3.7)$ & \\
\hline High blood pressure & $286(5.4)$ & $673(17.7)$ & & $276(9.3)$ & $361(12.1)$ & \\
\hline Metabolic acidosis & $271(5.1)$ & $230(6.1)$ & & $183(6.1)$ & $185(6.2)$ & \\
\hline Cardiac arrest & $131(2.5)$ & $153(4)$ & & $117(3.9)$ & $117(3.9)$ & \\
\hline Cardiogenic shock & $47(0.9)$ & $28(0.7)$ & & $23(0.8)$ & $26(0.9)$ & \\
\hline Anaphylactic shock & $40(0.8)$ & $10(0.3)$ & & $14(0.5)$ & $10(0.3)$ & \\
\hline Obstructive shock (PTE) & $14(0.3)$ & $26(0.7)$ & & $14(0.5)$ & $13(0.4)$ & \\
\hline
\end{tabular}

Numbers are presented as count (percentage) or mean \pm standard deviation 
disease $(6.9 \%$ vs $16.8 \%, \mathrm{SMD}=0.309)$ than did those detected by the RRS without any dedicated doctors. Similarly, the former group was more likely to have higher MEWS scores (mean 4.75 vs $4.03, \mathrm{SMD}=0.326$ ) and be detected at the medical department (78.3\% vs $64.3 \%$, $\mathrm{SMD}=0.322$ ) than was the latter group. The reasons for RRS activation differed significantly between the groups $(\mathrm{SMD}=0.499)($ Table 1$)$.

\section{Propensity score-matched analysis}

All variables presented in Table 1 were likely to affect both treatment assignment (detection by the RRS with dedicated doctors) and outcome (likelihood of survival) and were thus used to obtain the propensity score. After 1:1 matching, 2981 patients were included per group (RSS with vs. without dedicated doctors) (Fig. 1).

After matching, the groups were well-balanced with a SMD of $<0.1$ for all variables used to obtain the propensity score (Table 1). For details in changes to the SMDs per variable, see Additional file 2: Figure S1. The distribution of the propensity scores was similar between the groups after matching (Additional file 2: Figure S2).

\section{Impact on patient survival}

After propensity score matching, there was no betweengroup difference in overall survival outcomes (HR of death 1.05 , 95\% CI 0.93-1.2) (patients in the RSS with vs. without dedicated doctors). The Kaplan-Meier curve also showed a similar probability of survival for both groups after RSS activation (Fig. 2A).

\section{Impact on types of interventions}

A total of 10,488 interventions were performed in the general ward before ICU admission. General management consultation was the most common intervention performed (45.4\%), followed by portable sonography (7.2\%), CT imaging evaluation (6.7\%), and intubation (6.3\%) (Additional file 2: Table S1). Patients detected by the RRS with dedicated doctors tended to undergo more interventions before ICU admission than those detected by the RRS without any dedicated doctors. The interventions were arterial line insertion (OR 25.33, 95\% CI 15.12-42.44), kidney replacement therapy (OR 10.77, 95\% CI 6.10-19.01), bilevel positive airway pressure use (OR 10.00, 95\% CI 4.32-23.15), general management consultation (OR 6.37, 95\% CI 5.33-7.60), portable sonography $(5.26,95 \%$ CI $4.30-6.45)$, CT imaging evaluation (OR 4.81, 95\% CI 3.93-5.90), central line insertion (OR 2.40, 95\% CI 1.71-3.36), intubation (OR 1.60, 95\% CI 1.36-1.90), DNR consultation (OR 1.54, 95\% CI

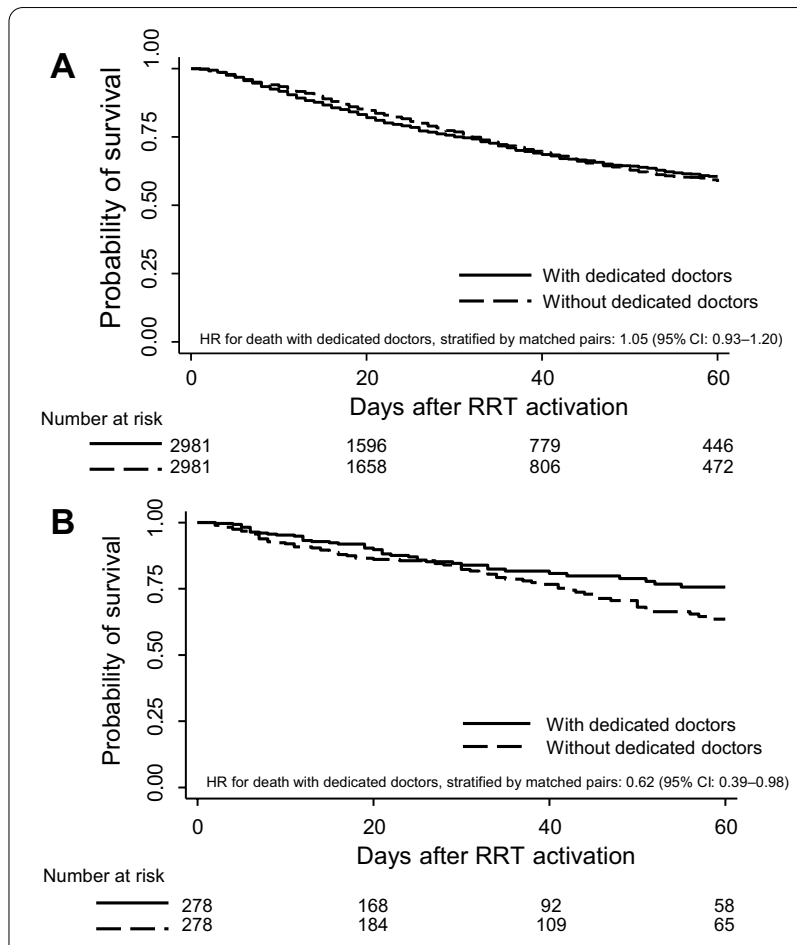

Fig. 2 Probability of survival according to the presence of dedicated doctors in the rapid response system. A Main analysis regardless of the reason for rapid response system activation. B Sensitivity analysis with patients diagnosed as sepsis or septic shock

1.30-1.82), and ICU admission (OR 1.31, 95\% CI 1.181.46). Conversely, these patients underwent less bronchoscopy (OR 0.43, 95\% CI 0.20-0.94) (Fig. 3A).

\section{Sensitivity analysis}

A total of 1012 patients with sepsis or septic shock were selected for sensitivity analysis, including 694 patients (68.6\%) detected by the RRS with dedicated doctors. After 1:1 matching using the covariates, 278 patients were included per group, with well-balanced characteristics in both groups (Table 2). The quick Sequential Organ Failure Assessment score showed a median of 1 point (interquartile range 1-2), with no significant difference between the two groups ( $P=0.189$ by Wilcoxon signed-rank test). The score revealed poor performance to predict the probability of in-hospital death (Harrell's c-index 0.58, 95\% CI 0.52-0.63). Cox regression analysis by matched pairs revealed that patients detected by the RRS with dedicated doctors revealed better survival rates than those detected by the RSS without any dedicated doctors (HR for death 0.62 with 95\% CI 0.30 0.98) (Fig. 2B).

For most interventions, no difference in incidence was detected between the groups due to a small number 


\section{A}

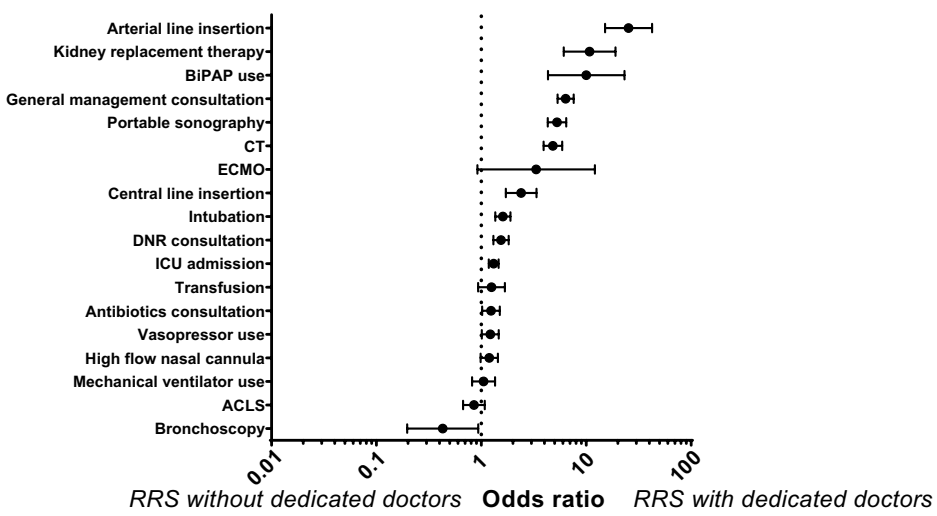

B

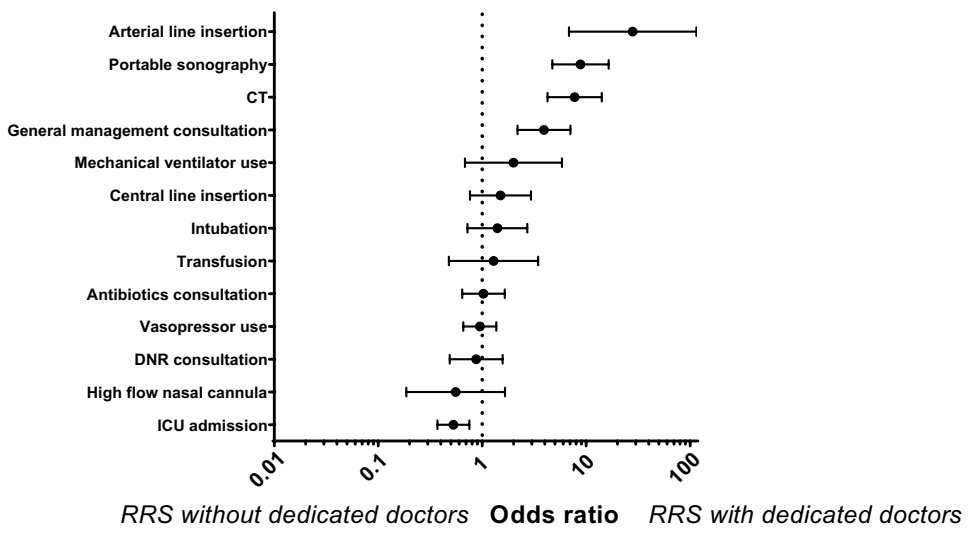

Fig. 3 Interventions performed according to the presence of dedicated doctors in the rapid response system. A Main analysis regardless of the reason for rapid response system activation. B Sensitivity analysis with patients diagnosed as sepsis or septic shock. Dots represent odds ratios and bars represent 95\% confidence intervals. Abbreviations: ACLS, advanced cardiovascular life support; BiPAP, bilevel positive airway pressure; CT, computed tomography; DNR, do not resuscitate; ECMO, extracorporeal membrane oxygenation; ICU, intensive care unit

of affected patients. However, patients detected by the RRS with dedicated doctors tended to undergo more arterial line insertion (OR 28.00, 95\% CI 6.83-114.70), portable sonography (OR $8.82,95 \%$ CI $4.73-16.45$ ), CT imaging evaluation (OR 7.75, 95\% CI 4.25-14.14), and general management consultation $(3.93,95 \%$ CI $2.19-$ 7.06), but less ICU admission (OR 0.53, 95\% CI $0.37-$ 0.75 ) than did those detected by the RRS without any dedicated doctors (Fig. 3B).

\section{Discussion}

In this propensity score-matched multicenter retrospective cohort study, the overall likelihood of survival among patients detected by the RRS was similar regardless of the presence of dedicated doctors. However, the presence of dedicated doctors in the RRS was associated with more frequent interventions such as arterial line insertion and kidney replacement therapy. Furthermore, patients with sepsis or septic shock in the RSS with dedicated doctors revealed a greater likelihood of survival and lower ICU admission rate than those in the RSS without any dedicated doctors.

Our study findings reflect previous controversies regarding the role of dedicated doctors in the RRS $[8,10$, 22-24]. Previously reported incidence of cardiac arrest and ICU transfer was similar when RRS was led by either senior residents or ICU physicians [22]; similarly, the rate of in-hospital death and length of stay estimates were similar when the RRS was driven by intensivists, nurses, or house staff [23]. Furthermore, a previous systematic review of 29 studies suggested that the presence of a physician in the RRS did not affect the rates of in-hospital mortality or cardiopulmonary arrest [10]. 
Table 2 Characteristics of patients diagnosed as sepsis or septic shock before and after propensity score matching

\begin{tabular}{|c|c|c|c|c|c|c|}
\hline \multirow[t]{2}{*}{ Variables } & \multicolumn{3}{|l|}{ Before matching } & \multicolumn{3}{|l|}{ After matching } \\
\hline & $\begin{array}{l}\text { RRS with dedicated } \\
\text { doctor } n=694\end{array}$ & $\begin{array}{l}\text { RRS without } \\
\text { dedicated doctor } \\
n=318\end{array}$ & SMD & $\begin{array}{l}\text { RRS with dedicated } \\
\text { doctor } n=278\end{array}$ & $\begin{array}{l}\text { RRS without } \\
\text { dedicated doctor } \\
n=278\end{array}$ & SMD \\
\hline Age, years & $62.25 \pm 13.2$ & $67.08 \pm 13.71$ & 0.359 & $65.76 \pm 12.25$ & $66.18 \pm 13.71$ & 0.032 \\
\hline Female sex & $287(41.4)$ & $150(47.2)$ & 0.117 & $131(47.1)$ & $128(46)$ & 0.022 \\
\hline $\mathrm{BMI}, \mathrm{kg} / \mathrm{m}^{2}$ & $22.35 \pm 4.24$ & $22.51 \pm 3.81$ & 0.040 & $22.57 \pm 4.36$ & $22.63 \pm 3.82$ & 0.015 \\
\hline \multicolumn{7}{|l|}{ Comorbidities } \\
\hline Solid malignancy & $347(50)$ & 107 (33.6) & 0.336 & $101(36.3)$ & $107(38.5)$ & 0.045 \\
\hline Diabetes mellitus & $175(25.2)$ & $99(31.1)$ & 0.132 & $79(28.4)$ & 85 (30.6) & 0.047 \\
\hline Hematologic malignancy & $154(22.2)$ & $24(7.5)$ & 0.421 & $31(11.2)$ & $23(8.3)$ & 0.097 \\
\hline Cardiovascular disease & $134(19.3)$ & $54(17)$ & 0.060 & 49 (17.6) & $49(17.6)$ & $<0.001$ \\
\hline Chronic HBP disease & $81(11.7)$ & $47(14.8)$ & 0.092 & $36(12.9)$ & $45(16.2)$ & 0.092 \\
\hline Chronic kidney disease & $45(6.5)$ & $37(11.6)$ & 0.180 & $30(10.8)$ & $31(11.2)$ & 0.012 \\
\hline Chronic lung disease & $40(5.8)$ & $30(9.4)$ & 0.139 & $21(7.6)$ & $21(7.6)$ & $<0.001$ \\
\hline Cerebrovascular disease & $40(5.8)$ & $49(15.4)$ & 0.317 & $26(9.4)$ & $31(11.2)$ & 0.059 \\
\hline Organ Transplantation & $33(4.8)$ & $10(3.1)$ & 0.083 & $10(3.6)$ & $9(3.2)$ & 0.020 \\
\hline Gastrointestinal disease & $18(2.6)$ & $29(9.1)$ & 0.281 & $13(4.7)$ & $18(6.5)$ & 0.078 \\
\hline Thyroid disease & $15(2.2)$ & $13(4.1)$ & 0.111 & $8(2.9)$ & $10(3.6)$ & 0.041 \\
\hline MEWS & $5.47 \pm 2.3$ & $5.05 \pm 2.27$ & 0.185 & $4.94 \pm 2.14$ & $5.09 \pm 2.28$ & 0.072 \\
\hline Department & & & 0.295 & & & 0.049 \\
\hline Medical & $566(81.6)$ & $224(70.4)$ & & $202(72.7)$ & $208(74.8)$ & \\
\hline Surgical & $124(17.9)$ & $94(29.6)$ & & $76(27.3)$ & $70(25.2)$ & \\
\hline Obstetrics & $4(0.6)$ & $0(0)$ & & - & - & \\
\hline Location & & & 0.054 & & & $<0.001$ \\
\hline General ward & $693(99.9)$ & $318(100)$ & & $278(100)$ & $278(100)$ & \\
\hline Others & $1(0.1)$ & $0(0)$ & & - & - & \\
\hline
\end{tabular}

Numbers are presented as count (percentage) or mean \pm standard deviation

HBP, hepato-biliary-pancreatic; MEWS, modified early warning score; RRS, rapid response system; SMD, standardized mean difference

Despite the increased incidence of interventions in the RRS in our study, similar survival outcomes can be explained by two different perspectives. First, in most circumstances, nurse-driven actions such as low-flow oxygen supplementation/adjustment may be sufficient in early-stage resuscitation. In our matched population, the most common reason for RRS activation was respiratory distress, affecting 2980 (50.0\%) patients; however, only 599 (20.1\%) of them required intubation. The predominance of low-flow oxygen titration after RRS activation has been previously reported [25]. Moreover, studies have shown that standard oxygen therapy may be non-inferior to high-flow oxygen supply [26] and that non-invasive ventilation may suffice, replacing invasive ventilation in acute respiratory failure [27]. Likewise, nurse-driven activities such as intravenous fluid or as-needed drug administration may suffice as primary management. In hypovolemic shock, which accounted for 305 (5.1\%) patients in our matched population, intravenous fluid therapy is the mainstay of treatment [28]. The administration of intravenous antihypertensive medication is the primary standard-of-care treatment for high blood pressure [29], which was the second most common reason for RRS activation in our study (637 [10.7\%] patients).

Second, interventions may be futile in the end stages of chronic illness. In our study, matched patients had underlying solid malignancy or hematologic malignancy in over $40 \%$ of cases. Although the proportion of endstage disease could not be ascertained, metabolic acidosis and altered mental state due to end-stage processes are difficult to reverse despite interventions. Moreover, the increased frequency of a DNR consultation after RRS activation may have decreased the survival rate upon discharge [30].

This is the first study to report better survival outcomes of patients with sepsis or septic shock among those detected by the RRS with dedicated doctors than those detected by the RSS without such doctors. The 
recent Surviving Sepsis Campaign Bundle has introduced a 1-h bundle, which includes obtaining blood cultures, administrating antibiotics, and aggressively resuscitating the patient with intravenous fluid and vasopressors within $1 \mathrm{~h}$ of detection [17]. Moreover, invasive arterial pressure monitoring has been recommended to identify the specific anatomic origin of infection and decide whether emergent source control is required [18]. These recommendations are concordant with our study findings. Dedicated doctors underwent arterial line insertion for invasive blood pressure monitoring, checked sonography/CT for anatomic evaluation of infection, and provided general management consultation for the overall process of the 1-h bundle. These interventions may be beneficial to patients with sepsis or septic shock and may improve survival outcomes and lower the rates of ICU admissions [31].

Overall, the present findings suggest that the presence of dedicated doctors within the RSS may be helpful in particular situations, especially for those where the implementation of early bundle-based approaches is required. Considering the high incidence of sepsis among patients detected by the RRS [32], aggressive evaluation and intervention by a dedicated doctor should be recommended when either sepsis or septic shock is suspected. Future prospective studies are required to confirm the beneficial impact of dedicated doctors in the RRS on patients in need of bundle-based approaches.

This study had some limitations. First, some aspects of RRS in each center were not evaluated, such as staff communication skills or leadership during the RRS-activating event or the clarity of team members' roles [8], all of which are potentially relevant. Second, this was a multicenter retrospective observational study based on South Korean patients. Although the propensity score matching method was used, it should be interpreted with caution. Further studies are required to generalize the results to other ethnic populations.

\section{Conclusions}

The presence of dedicated doctors in the RRS was not associated with the overall patient survival estimates. However, compared with that without, the RRS with dedicated doctors was associated with more frequent interventions and was associated with improved survival outcomes and lesser ICU admission rates among patients with sepsis or septic shock.

\section{Abbreviations}

Cl: Confidence interval; CT: Computed tomography; DNR: Do not resuscitate; HR: Hazard ratio; ICU: Intensive care unit; MEWS: Modified Early Warning Score; OR: Odds ratio; RRS: Rapid response system; SMD: Standardized mean difference.

\section{Supplementary Information}

The online version contains supplementary material available at https://doi. org/10.1186/s12931-021-01824-7.

Additional file 1: Activation criteria of the rapid response systems according to each center (anonymized)

Additional file 2: Figure S1. Change of the values of standardized mean differences before and after propensity score matching. Figure S2. Distribution of the propensity scores before and after matching. Table S1. Overall incidence of interventions performed after the activation of the rapid response system in the matched population.

\section{Acknowledgements}

The authors deeply appreciate the coordinators including Jee Hwan Ahn and Eun Mi Cho for their support during data collection.

\section{Authors' contributions}

HJK, YJL contributed to the conception and design of the work. KJ, BJK, JJA, SBH, DHL, JYM, JSK, JP, JHC, SML, and YJL contributed to the data acquisition. $\mathrm{HJK}, \mathrm{KJ}$, and $Y J \mathrm{~L}$ contributed to the analysis and interpretation of the data for the work. HJK drafted the article. KJ, BJK, JJA, SBH, DHL, JYM, JSK, JP, $J H C, S M L$, and YJL revised it critically for important intellectual content. All authors agreed to be accountable for all aspects of the work, in ensuring that questions related to the accuracy or integrity of any part of the work are appropriately investigated and resolved. All authors read and approved the final manuscript.

\section{Funding}

This research was supported by a grant of the Korea Health Technology R\&D Project through the Korea Health Industry Development Institute (KHIDI), funded by the Ministry of Health \& Welfare, Republic of Korea (HI18C0599). The funders did not have any roles in this study.

\section{Availability of data and materials}

The datasets used and/or analyzed during the current study are available from the corresponding author on reasonable request.

\section{Declarations}

Ethics approval and consent to participate

The development of this cohort was approved by the Institutional Review Board of each center. The need for informed consent was waived due to the observational nature of the study and use of anonymized data. Our study was conducted in accordance with the amended Declaration of Helsinki.

\section{Consent for publication}

Not applicable.

\section{Competing interests}

The authors declare that they have no competing interests.

\section{Author details}

${ }^{1}$ Division of Pulmonary and Critical Care Medicine, Department of Internal Medicine, Seoul National University Bundang Hospital, Seongnam, Republic of Korea. ${ }^{2}$ Department of Critical Care Medicine, Samsung Medical Center, Sungkyunkwan University School of Medicine, Seoul, Republic of Korea. ${ }^{3}$ Department of Internal Medicine, Ulsan University Hospital, University of Ulsan College of Medicine, Ulsan, Republic of Korea. ${ }^{4}$ Department of Pulmonary and Critical Care Medicine, Asan Medical Center, University of Ulsan College of Medicine, Seoul, Republic of Korea. ${ }^{5}$ Division of Pulmonary and Critical Care Medicine, Department of Internal Medicine, Dong-A University College of Medicine, Busan, Republic of Korea. ${ }^{6}$ Division of Pulmonary and Critical Care Medicine, Department of Internal Medicine, Chungnam National University Hospital, Chungnam National University College of Medicine, Daejeon, Republic of Korea. ${ }^{7}$ Division of Pulmonary and Critical Care Medicine, Department of Internal Medicine, Inha University Hospital, Inha University School of Medicine, Incheon, Republic of Korea. ${ }^{8}$ Division of Pulmonology, 
Department of Internal Medicine, CHA University, CHA Bundang Medical Center, Seongnam, Republic of Korea. ${ }^{9}$ Division of Pulmonology, Department of Internal Medicine, Gangnam Severance Hospital, Yonsei University College of Medicine, Seoul, Republic of Korea. ${ }^{10}$ Division of Pulmonary and Critical Care Medicine, Department of Internal Medicine, Seoul National University Hospital, Seoul National University College of Medicine, Seoul, Republic of Korea.

Received: 14 June 2021 Accepted: 14 Auqust 2021

Published online: 26 August 2021

\section{References}

1. Jones DA, DeVita MA, Bellomo R. Rapid-response teams. N Engl J Med. 2011;365(2):139-46

2. Franklin C, Mathew J. Developing strategies to prevent inhospital cardiac arrest: analyzing responses of physicians and nurses in the hours before the event. Crit Care Med. 1994;22(2):244-7.

3. Berwick DM, Calkins DR, McCannon CJ, Hackbarth AD. The 100,000 lives campaign: setting a goal and a deadline for improving health care quality. JAMA. 2006;295(3):324-7.

4. Solomon RS, Corwin GS, Barclay DC, Quddusi SF, Dannenberg MD. Effectiveness of rapid response teams on rates of in-hospital cardiopulmonary arrest and mortality: a systematic review and meta-analysis. J Hosp Med. 2016;11(6):438-45.

5. Lyons PG, Edelson DP, Churpek MM. Rapid response systems. Resuscitation. 2018;128:191-7.

6. Kim Y, Lee DS, Min H, Choi YY, Lee EY, Song I, et al. Effectiveness analysis of a part-time rapid response system during operation versus nonoperation. Crit Care Med. 2017:45(6):e592-9.

7. Stolldorf DP, Jones CB. Deployment of rapid response teams by 31 hospitals in a statewide collaborative. Jt Comm J Qual Patient Saf. 2015;41(4):186-91.

8. Nallamothu BK, Guetterman TC, Harrod M, Kellenberg JE, Lehrich JL Kronick SL, et al. How do resuscitation teams at top-performing hospitals for in-hospital cardiac arrest succeed? A qualitative study. Circulation. 2018;138(2):154-63.

9. Martin-Misener R, Harbman P, Donald F, Reid K, Kilpatrick K, Carter N, et al. Cost-effectiveness of nurse practitioners in primary and specialised ambulatory care: systematic review. BMJ Open. 2015;5(6):e007167.

10. Maharaj R, Raffaele I, Wendon J. Rapid response systems: a systematic review and meta-analysis. Crit Care. 2015;19(1):254.

11. Subbe CP, Kruger M, Rutherford P, Gemmel L. Validation of a modified Early Warning Score in medical admissions. QJM. 2001;94(10):521-6.

12. Rosenbaum PR, Rubin DB. The central role of the propensity score in observational studies for causal effects. Biometrika. 1983;70(1):41-55.

13. Austin PC. An introduction to propensity score methods for reducing the effects of confounding in observational studies. Multivariate Behav Res. 2011;46(3):399-424.

14. Baser $\mathrm{O}$. Too much ado about propensity score models? Comparing methods of propensity score matching. Value Health. 2006;9(6):377-85

15. Austin PC. A critical appraisal of propensity-score matching in the medical literature between 1996 and 2003. Stat Med. 2008;27(12):2037-49.

16. Austin PC. Comparing paired vs non-paired statistical methods of analyses when making inferences about absolute risk reductions in propensity-score matched samples. Stat Med. 2011:30(11):1292-301.

17. Levy MM, Evans LE, Rhodes A. The surviving sepsis campaign bundle: 2018 update. Intensive Care Med. 2018:44(6):925-8.
18. Rhodes A, Evans LE, Alhazzani W, Levy MM, Antonelli M, Ferrer R, et al. Surviving sepsis campaign: international guidelines for management of sepsis and septic shock: 2016. Intensive Care Med. 2017;43(3):304-77.

19. Seymour CW, Liu VX, Iwashyna TJ, Brunkhorst FM, Rea TD, Scherag A, et al. Assessment of clinical criteria for sepsis: for the third international consensus definitions for sepsis and septic shock (Sepsis-3). JAMA. 2016;315(8):762-74.

20. Zhang Z, Kim HJ, Lonjon G, Zhu Y, written on behalf of AMEB-DCTCG. Balance diagnostics after propensity score matching. Ann Transl Med. 2019;7(1):16.

21. Ho DE, Imai K, King G, Stuart EA. Matchlt: nonparametric preprocessing for parametric causal inference. J Stat Softw. 2011;42(8):28.

22. Morris DS, Schweickert W, Holena D, Handzel R, Sims C, Pascual JL, et al. Differences in outcomes between ICU attending and senior resident physician led medical emergency team responses. Resuscitation. 2012:83(12):1434-7

23. Karvellas CJ, de Souza IA, Gibney RT, Bagshaw SM. Association between implementation of an intensivist-led medical emergency team and mortality. BMJ Qual Saf. 2012;21(2):152-9.

24. Hall C, Samanta R, Trivedi M. Would your hospital benefit from a dedicated rapid response doctor? J Intensive Care Soc. 2020. https://doi.org/ $10.1177 / 1751143720903234$.

25. Lee YJ, Lee DS, Min H, Choi YY, Lee EY, Song I, et al. Differences in the clinical characteristics of rapid response system activation in patients admitted to medical or surgical services. J Korean Med Sci. 2017;32(4):688-94.

26. Azoulay E, Lemiale V, Mokart D, Nseir S, Argaud L, Pene F, et al. Effect of high-flow nasal oxygen vs standard oxygen on 28-day mortality in immunocompromised patients with acute respiratory failure: the $\mathrm{HIGH}$ randomized clinical trial. JAMA. 2018;320(20):2099-107.

27. Nava S, Hill N. Non-invasive ventilation in acute respiratory failure. Lancet. 2009:374(9685):250-9.

28. Annane D, Siami S, Jaber S, Martin C, Elatrous S, Declere AD, et al. Effects of fluid resuscitation with colloids vs crystalloids on mortality in critically ill patients presenting with hypovolemic shock: the CRISTAL randomized trial. JAMA. 2013;310(17):1809-17.

29. Suneja M, Sanders ML. Hypertensive emergency. Med Clin North Am. 2017;101(3):465-78.

30. Richardson DK, Zive D, Daya M, Newgard CD. The impact of early do not resuscitate (DNR) orders on patient care and outcomes following resuscitation from out of hospital cardiac arrest. Resuscitation. 2013;84(4):483-7.

31. Leisman DE, Doerfler ME, Ward MF, Masick KD, Wie BJ, Gribben JL, et al. Survival benefit and cost savings from compliance with a simplified 3-hour sepsis bundle in a series of prospective, multisite, observational cohorts. Crit Care Med. 2017;45(3):395-406.

32. Cross G, Bilgrami I, Eastwood G, Johnson P, Howden BP, Bellomo R, et al. The epidemiology of sepsis during rapid response team reviews in a teaching hospital. Anaesth Intensive Care. 2015;43(2):193-8.

\section{Publisher's Note}

Springer Nature remains neutral with regard to jurisdictional claims in published maps and institutional affiliations.

Ready to submit your research? Choose BMC and benefit from:

- fast, convenient online submission

- thorough peer review by experienced researchers in your field

- rapid publication on acceptance

- support for research data, including large and complex data types

- gold Open Access which fosters wider collaboration and increased citations

- maximum visibility for your research: over 100M website views per year

At $B M C$, research is always in progress.

Learn more biomedcentral.com/submissions 